\title{
DIAGNÓSTICO DA ARBORIZAÇÃO URBANA DE DUAS VIAS NA CIDADE DE SANTA ROSA - RS
}

\author{
Maiara Dall Aqua ${ }^{1}$, Nilvane Teresinha Ghellar Müller²
}

\section{RESUMO}

A arborização viária é essencial na composição da vegetação urbana, desempenhando importante papel na manutenção das cidades. Assim, o trabalho objetivou descrever a arborização urbana por meio de um inventário quali e quantitativo das espécies arbóreas e arbustivas em duas avenidas de Santa Rosa/RS, do tipo censo, através de observação direta e registro fotográfico. Para a identificação das espécies botânicas coletadas foi utilizada literatura especializada. Para descrever cada indivíduo qualitativamente foram observados a condição fitossanitária, o desenvolvimento do sistema radicular, em relação a calçada e o desenvolvimento da copa relacionadas a rede elétrica. O inventário resultou em 433 indivíduos, distribuídos em 58 espécies e 30 famílias. As famílias com maior número de espécies foram: Fabaceae (74), Bignoniaceae (53), Myrtaceae (30), e Arecaceae (28). A espécie mais frequente foi a Lagerstroemia indica L. (9,9\%). A maioria das plantas $(97,2 \%)$ encontra-se em estado fitossanitário bom e regular, sendo que apenas $2,8 \%$ estão em condição ruim. Os resultados revelam que as vias de Santa Rosa possuem diversas espécies vegetais, havendo predominância de espécies exóticas em relação às nativas, porém, muitas delas são cultivadas em locais inadequados para o seu porte, devido à presença de rede elétrica e/ou calçadas.

Palavras-chave: Biodiversidade; Avenida; Vegetação urbana.

Recebido em 28.11.2013 e aceito em 19.05.2015

${ }^{1}$ Bióloga, Universidade Regional Integrada do alto Uruguai e Missões, Rua Universidade das Missões, 464, 98802-470, Santo Ângelo/RS, maiadall@hotmail.com

${ }^{2}$ Bióloga/Dra., Universidade Regional Integrada do alto Uruguai e Missões, Rua Universidade das Missões, 464, 98802-470, Santo Ângelo/RS, nil@santoangelo.uri.br 


\section{DIAGNOSIS OF THE URBAN FORESTATION OF TWO ROADS IN THE CITY OF SANTA ROSA - RS}

\section{ABSTRACT}

The street arborization is essential in the composition of the urban vegetation, playing na important role in the maintainance of cities. Thus, the purpose of the work was to describe the urban forestation through a quali and quantitative on the type census inventory of the tree and bush species at two avenues in the city of Santa Rosa/RS through direct observation and photographic record. Specialized literature has been used to identify the botanical species collected. Each individual has been described qulitatively, in this regard, the phytosanitary conditions have been observed, the development of rood system in relation to the sidewalk and the development of the treetop related to the eletric net. The inventory resulted in 433 individuals, distributed in 58 species and 30 families. The families with higher number of species were Fabaceae (74), Bignoniaceae (53), Myrtaceae (30), e Arecaceae (28). The most frequent specie was Lagerstroemia indica L. (9,9\%). The most of the plants $(97,2 \%)$ are in good and regular health, while only $2,8 \%$ are in bad condition. The results revealed that the roads of Santa Rosa have a wide diversityof plant species, with predominance of exotic compared to native, however, many of them are grown in places that don't match their size, due to the presence of eletrical wiring and/ or sidewalks.

Keywords: Biodiversity; Avenue; Urban vegetation.

\section{INTRODUÇÃO}

No Brasil em torno de $85 \%$ da população vive em áreas urbanas (IBGE, 2010), onde o clima difere consideravelmente de ambientes naturais. As cidades distanciam-se cada vez mais da natureza, mantendo-se, de certa forma cada vez mais artificial (JÚNIOR, 2011).

A capacidade de absorção de calor de superfícies urbanas como o asfalto, paredes de tijolo ou concreto, telhas de barro e de amianto, geralmente são refletores e contribuem para o aumento da temperatura. Somando a isso, a impermeabilização dos solos causa 
grandes problemas na medida em que evitam ou impedem a infiltração da água, forçando-a a escoar pela superfície de áreas cimentadas, aumentando seu volume e deslocando o material orgânico e lixos que possam estar nas ruas. Isso muitas vezes provoca enchentes, uma vez que os rios não conseguem absorver um volume tão grande de água num curto espaço de tempo.

Uma maneira de minimizar tal situação pode ocorrer através do uso adequado de espécies de vegetais. Além do embelezamento do local, a arborização quando bem planejada traz excelentes benefícios e boa qualidade de vida para todos os moradores. Pois as árvores atuam no controle da temperatura e ajudam na diminuição dos ruídos provocados pela poluição sonora, também tem fatores de proteção quando reduzem a velocidade dos ventos e purificam o ar (LORENZI, 2002).

Por outro lado, para que a presença da árvore na via pública não venha a trazer transtornos futuros, é necessário conhecer as suas características morfológicas e fisiológicas. A escolha da espécie deve ser criteriosa, selecionando aquelas que são adequadas para cada rua ou cidade. Deve apresentar o maior número possível de quesitos técnicos que conferem com o local de plantio, como o sistema radicular da espécie, o porte da planta, o diâmetro da copa e sua finalidade naquele espaço, seja ela como sombra, no paisagismo ou como alimento. Tais cuidados devem ser observados, principalmente, se o vegetal for plantado em calçadas e passeios públicos, tendo-se plena ciência de que é impossível encontrar a árvore ideal para esse fim (DANTAS; SOUZA, 2004). Outros fatores que também devem ser levados em consideração são o clima e o tipo de solo de cada local, a diversificação das espécies a serem utilizadas, bem como, dar preferência a espécies nativas da região.

A cidade Santa Rosa, localizada ao noroeste do estado do Rio Grande do Sul, caracteriza-se por apresentar bastante vegetação em sua malha viária. Entretanto, verificase que algumas espécies apresentam idade avançada e muitas vezes com uma condição fitossanitária comprometida. Por outro lado, muitas destas espécies estão sendo removidas e substituídas por outras plantas, porém, ainda pode ser visualizada, em alguns locais, a ausência de reposição vegetal.

Como a arborização viária é essencial na composição urbana, desempenhando importante papel na manutenção das cidades, além de merecer destaque cada vez maior pelos seus benefícios e, até mesmo, dos problemas que se apresentam em função da presença da árvore no contexto urbano, aliado ao fato dos estudos sobre arborização na cidade de Santa Rosa ser recente, salienta-se a necessidade de desenvolver trabalhos nesta área. As avenidas selecionadas se devem ao fato de uma delas estar localizada no 
centro da cidade e a outra interliga esta com o Parque de Exposições Alfredo Leandro Carlson, além de servir de ligação com a BR 472. À vista disso, o presente estudo objetivou realizar um levantamento quali-quantitativo das espécies arbóreas e arbustivas utilizadas na arborização de duas vias, uma de acesso e uma do centro, da cidade de Santa Rosa- RS.

\section{MATERIAIS E MÉTODOS}

O estudo foi desenvolvido no perímetro urbano de Santa Rosa-RS. O município compreende uma área de $490 \mathrm{~km}^{2}$, com população de 68.573 habitantes (IBGE, 2010),

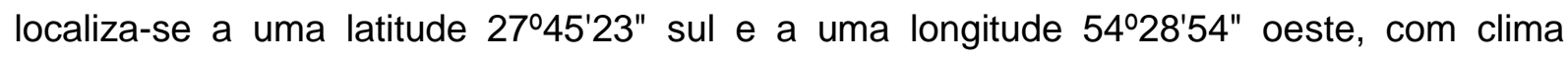
subtropical úmido e temperatura média anual de $17^{\circ} \mathrm{C}$. Está inserido no bioma Mata Atlântica, na região fitoecológica da Floresta Estacional Decidual (RIO GRANDE DO SUL, 2010).

Este tipo de vegetação é caracterizado por duas estações climáticas bem demarcadas. No Rio Grande do Sul, embora o clima apresenta chuvas bem distribuídas durante o ano e verões quentes, possui uma curta época muito fria e que ocasiona, provavelmente, a estacionalidade fisiológica da vegetação. Esta formação ocorre na forma de disjunções florestais apresentando o estrato dominante predominantemente caducifólio, com mais de $50 \%$ dos indivíduos despidos de folhas no período frio (IBGE, 1992).

A metodologia empregada consistiu, no levantamento da arborização pelo método de inventário quali-quantitativo do tipo censo, considerando todos os indivíduos vegetais de porte arbóreo e arbustivo, existentes em duas avenidas: Avenida Tuparendi e a sua extensão (Rua Henrique Gassen com 1,2 Km) e a Avenida Rio Branco através de observação direta e registro fotográfico. Tais locais foram selecionados devido ao fato das vias serem os principais pontos de acesso à cidade, além de haver grande circulação de trânsito em relação às demais vias urbanas de Santa Rosa. Para a identificação das espécies botânicas coletadas foi utilizada literatura especializada e a classificação das famílias seguiu o sistema de APG II utilizado por Souza e Lorenzi (2005) e Judd et al. (2009).

Para descrever cada indivíduo de maneira qualitativa, foi criada uma adaptação do método empregado no trabalho de Faria e Monteiro (2007), onde foram observadas as seguintes características:

a) Fitossanidade: Boa - árvore vigorosa e sadia, sem sinais aparentes de ataque de insetos, doenças ou injúrias mecânicas, pequena ou nenhuma necessidade de 
manutenção, forma ou arquitetura característica da espécie; Regular - média condição de vigor e saúde, necessita de pequenos reparos ou poda, apresenta descaracterização da forma, apresenta sinais de ataque de insetos, doença ou problemas fisiológicos; Ruim - avançado e irreversível declínio, apresenta ataque muito severo por insetos, doença ou injúria mecânica, descaracterizando sua arquitetura ou desequilibrando o vegetal, problemas fisiológicos cujos reparos não resultarão em benefício para o indivíduo.

b) Desenvolvimento do sistema radicular das árvores em relação à calçada: Presença de danos ao pavimento, quando o sistema radicular interfere na calçada, e Ausência de danos ao pavimento, quando o sistema radicular não interfere na calçada;

c) Desenvolvimento da copa das árvores em relação à rede elétrica: Presença de danos a rede elétrica - quando a espécie pelo seu crescimento normal está em contato com algum equipamento ou edificação, e Ausência de danos a rede elétrica quando a espécie pelo seu crescimento normal não está em contato com algum equipamento ou edificação.

O índice de diversidade calculado neste trabalho foi aquele proposto por Margalef (1951) em que:

\section{Alfa $=(S-1) / \log N$}

Onde:

Alfa: índice de diversidade

S: número de espécies

N: número de indivíduos (COSTA; LINK E MEDINA, 1993)

Os valores inferiores a 2,0 são considerados como aparentando áreas de baixa diversidade e valores superiores a 5,0 são considerados como indicador de grande diversidade.

A frequência das espécies no estudo (\%) foi obtida através da razão entre o número de indivíduos registrados da espécie e o número total de indivíduos registrados no estudo (BLUM, 2008).

O diagnóstico foi realizado com o uso de uma planilha de levantamento de dados, onde foram anotados os dados referentes aos indivíduos vegetais existentes. As visitas para coleta de dados ocorreram durante o mês de janeiro de 2013. Com base nos dados 
levantados, foi calculada a porcentagem de cada espécie ocorrente na área de estudo através do programa Microsoft Office Excel 2007.

\section{RESULTADOS E DISCUSSÃO}

$\mathrm{Na}$ área pesquisada constatou-se um total de 433 indivíduos vegetais, entre arbóreos e arbustivos, distribuídos em 30 famílias e 58 espécies (Tabela 1). As famílias mais abundantes em espécies foram: Fabaceae (17\%), Bignoniaceae (12,3\%), Myrtaceae (7\%) e Arecaceae (6,4\%). No estudo de Motter (2012) em Tuparendi-RS, cidade vizinha, também foi encontrado maior representatividade de espécies nas três primeiras famílias citadas. Já Boeni e Silveira (2011), em Porto Alegre-RS, encontraram maior representatividade nas famílias Fabaceae, Myrtaceae e Arecaceae.

A família Fabaceae destaca-se em relação as demais famílias na presente pesquisa, pois corresponde a uma das maiores famílias de angiospermas, com cerca de 18 mil espécies (SOUZA; LORENZI, 2005). As inúmeras espécies dessa família são empregadas como ornamentais, sendo inclusive a principal família utilizada na arborização urbana das cidades brasileiras (SOUZA; LORENZI, 2005). Myrtaceae é uma das famílias reconhecidamente abundantes em várias formações vegetacionais do Brasil, destacando-se sempre entre famílias mais representativas nos inventários florísticos (ROSA, 2009).

A área de abrangência deste estudo representa uma diversidade de espécies significativa, apesar de ser encontrado muitas vezes apenas um exemplar de cada espécie. De acordo com as recomendações de Grey e Deneke (1978), cada espécie deve permanecer em torno de 10 a $15 \%$ do total de indivíduos da população arbórea de um município.

Tabela 1. Distribuição quali-quantitativa das espécies da arborização urbana da cidade Santa Rosa-RS/2013. ( $\mathrm{E}=$ exótica, $\mathrm{N}=$ nativa, $\mathrm{NI}=$ número de indivíduo, $\mathrm{Fr}=$ frequência relativa)

Table 1. Qualitative and quantitative distribution of the species of the urban growing of trees in the city of Santa Rosa-RS/2013 ( $\mathrm{E}=$ exotic, $\mathrm{N}=$ native, $\mathrm{NI}=$ number of individual, $\mathrm{Fr}=$ relative frequency)

\begin{tabular}{|l|l|l|l|c|c|}
\hline \multicolumn{1}{|c|}{$\begin{array}{c}\text { Nome } \\
\text { Popular }\end{array}$} & \multicolumn{1}{|c|}{ Nome Científico } & \multicolumn{1}{c|}{ Família } & \multicolumn{1}{c|}{ Origem } & NI & Fr (\%) \\
\hline Extremosa & Lagerstroemia indica L. & Lythraceae & E (Ásia) & 43 & 9,93 \\
\hline Canafístula & $\begin{array}{l}\text { Peltophorum dubium (Spreng.) } \\
\text { Taub. }\end{array}$ & Fabaceae & N & 24 & 5,54 \\
\hline Canela & Cinnamomum camphora (L.) J. & Lauraceae & E (China) & 23 & 5,31 \\
\hline
\end{tabular}




\begin{tabular}{|c|c|c|c|c|c|}
\hline & Presl & & & & \\
\hline Ipê-roxo & $\begin{array}{l}\text { Handroanthus heptaphyllus } \\
\text { (Mart.) Mattos }\end{array}$ & Bignoniaceae & $\mathrm{N}$ & 23 & 5,31 \\
\hline Ipê-de-várzea & $\begin{array}{l}\text { Handroanthus } \\
\text { chrysotrichus (Mart. ex A.DC.) } \\
\text { Mattos }\end{array}$ & Bignoniaceae & $\mathrm{N}$ & 22 & 5,08 \\
\hline Ligustro & Ligustrum lucidum. Aiton. & Oleaceae & E (China) & 21 & 4,85 \\
\hline Cinamomo & Melia azedarach L. & Meliaceae & E (China) & 20 & 4,62 \\
\hline Pingo-de-ouro & Duranta repens L. & Verbenaceae & $\begin{array}{l}\text { E (América } \\
\text { Central e do } \\
\text { Sul) }\end{array}$ & 19 & 4,39 \\
\hline Sibipiruna & $\begin{array}{l}\text { Caesalpinia peltophoroides } \\
\text { Benth }\end{array}$ & Fabaceae & $\mathrm{N}$ & 18 & 4,16 \\
\hline Falsa-murta & Murraya paniculata (L.) Jacq. & Rutaceae & E (Ásia) & 17 & 3,93 \\
\hline $\begin{array}{l}\text { Canela-da- } \\
\text { índia }\end{array}$ & $\begin{array}{l}\text { Cinnamomum burmannii (Ness } \\
\& \text { T. Ness) Blume }\end{array}$ & Lauraceae & E (Ásia) & 16 & 3,70 \\
\hline Flamboyant & $\begin{array}{l}\text { Delonix regia (Bojer ex Hook.) } \\
\text { Raf }\end{array}$ & Fabaceae & $\mathrm{E}$ (África) & 15 & 3,46 \\
\hline Jabuticaba & $\begin{array}{l}\text { Myrciaria cauliflora (Mart.) O. } \\
\text { Berg }\end{array}$ & Myrtaceae & $\mathrm{N}$ & 14 & 3,23 \\
\hline $\begin{array}{l}\text { Coqueiro- } \\
\text { jerivá }\end{array}$ & $\begin{array}{l}\text { Syagrus romanzoffiana (Cham.) } \\
\text { Glassam. }\end{array}$ & Arecaceae & $\mathrm{N}$ & 13 & 3,00 \\
\hline Buxo & Buxus sempervirens L. & Buxuceae & E (Ásia) & 12 & 2,77 \\
\hline $\begin{array}{l}\text { Figueira-de- } \\
\text { jardim }\end{array}$ & Ficus auriculata Lour & Moraceae & E (Ásia) & 11 & 2,54 \\
\hline Uva-japonesa & Hovenia dulcis Thunb. & Rhamnaceae & $\begin{array}{l}\text { E (Japão e } \\
\text { China) }\end{array}$ & 10 & 2,31 \\
\hline Fênix & Phoenix roebelenii O’Brien & Arecaceae & E (Ásia) & 10 & 2,31 \\
\hline Jacarandá & Jacaranda micrantha Cham. & Bignoniaceae & $\mathrm{N}$ & 7 & 1,62 \\
\hline Fícus & Ficus Benjamina Variegata & Moraceae & $\begin{array}{l}\text { E (Índia e } \\
\text { China) }\end{array}$ & 6 & 1,39 \\
\hline Hibisco & Hibiscus rosa-sinensis L. & Malvaceae & $\mathrm{E}$ (Ásia) & 5 & 1,15 \\
\hline Ingá-feijão & Inga marginata Wild. & Fabaceae & $\mathrm{N}$ & 5 & 1,15 \\
\hline Thuja & Thuja sp. & Cupressaceae & $\begin{array}{l}\text { E (América } \\
\text { do Norte) }\end{array}$ & 5 & 1,15 \\
\hline Ariticum & Rollinia sp. & Annonaceae & $\mathrm{N}$ & 5 & 1,15 \\
\hline Ingá-banana & Inga uruguensis Hook. \& Arn. & Fabaceae & $\mathrm{N}$ & 4 & 0,92 \\
\hline Goiabeira & Psidium guajava L. & eae & $\mathrm{N}$ & 4 & 0,92 \\
\hline $\begin{array}{l}\text { Palmeira- } \\
\text { Imperial }\end{array}$ & $\begin{array}{l}\text { Roystonea oleracea (Jacq.) O. } \\
\text { F. Cook }\end{array}$ & Arecaceae & $\begin{array}{l}\text { E (América } \\
\text { do Sul) }\end{array}$ & 4 & 0,92 \\
\hline Tipuana & Tipuana tipu (Benth.) Kuntze & Fabaceae & $\begin{array}{l}\text { E (Argentina } \\
\text { e Bolívia) }\end{array}$ & 4 & 0,92 \\
\hline Cipreste & Chamae cyparis sp. & Cupressaceae & E (Ásia) & 3 & 0,69 \\
\hline $\begin{array}{l}\text { Escova-de- } \\
\text { garrafa }\end{array}$ & $\begin{array}{l}\text { Callistemon viminalis (Sol. ex } \\
\text { Gaertn.) G. Don }\end{array}$ & Myrtaceae & E (Austrália) & 3 & 0,69 \\
\hline Guabiju & $\begin{array}{l}\text { Myrcianthes pungens (O. Berg) } \\
\text { D. Legrand }\end{array}$ & Myrtaceae & $\mathrm{N}$ & 3 & 0,69 \\
\hline Jambolão & $\begin{array}{l}\text { Syzygium jambolanum (Lam.) } \\
\text { DC. }\end{array}$ & Myrtaceae & E (Índia) & 3 & 0,69 \\
\hline Louro-pardo & $\begin{array}{l}\text { Cordia trichotoma (Vell.) Arrab. } \\
\text { Ex. Steud }\end{array}$ & Boraginaceae & $\mathrm{N}$ & 3 & 0,69 \\
\hline $\begin{array}{l}\text { Manacá-de- } \\
\text { cheiro }\end{array}$ & $\begin{array}{l}\text { Brunfelsia uniflora (Pohl) D. } \\
\text { Don }\end{array}$ & Solanaceae & $\mathrm{N}$ & 3 & 0,69 \\
\hline Quaresmeira & Tibouchina granulosa Cogn. & Melastomaceae & $\mathrm{N}$ & 3 & 0,69 \\
\hline
\end{tabular}




\begin{tabular}{|c|c|c|c|c|c|}
\hline Aroeira-salsa & Schinus molle L. & Anacardiaceae & $\mathrm{N}$ & 2 & 0,46 \\
\hline Acoita-cavalo & Luehea divaricata Mart. ex Zucc & Tiliaceae & $\mathrm{N}$ & 2 & 0,46 \\
\hline $\begin{array}{l}\text { Pinheiro-de- } \\
\text { Buda }\end{array}$ & $\begin{array}{l}\text { Podocarpus macrophyllus } \\
\text { (Thunb.) Sweet }\end{array}$ & Podocarpaceae & E (Ásia) & 2 & 0,46 \\
\hline Fiqueira & Ficus luschnatiana (Miq.) Miq. & Moraceae & $\mathrm{N}$ & 2 & 0,46 \\
\hline Grevilha & $\begin{array}{l}\text { Grevillea robusta A. Cunn. Ex. } \\
\text { R. Br. }\end{array}$ & Proteaceae & E (Aus & 2 & 0,46 \\
\hline Pau-ferro-liso & $\begin{array}{l}\text { Caesalpinia ferrea ex. Tul. var. } \\
\text { leiostachya Benth. }\end{array}$ & Fabaceae & $\mathrm{N}$ & 2 & 0,46 \\
\hline Pinus & Pinus eilliottii Engel & Pinaceae & $E(E U A)$ & 2 & 0,46 \\
\hline Pitanga & Eugenia uniflora L. & Myrtaceae & $\mathrm{N}$ & 2 & 0,46 \\
\hline Plumeria & Plumeria rubra L. & Apocynaneae & $\begin{array}{l}\text { E (América } \\
\text { Central) }\end{array}$ & 2 & 0,46 \\
\hline Amora & Morus nigra L. & Moraceae & $\mathrm{E}$ (Ásia) & 1 & 0,23 \\
\hline Angico & $\begin{array}{l}\text { Parapiptadenia rígida (Benth.) } \\
\text { Brenan }\end{array}$ & Fabaceae & $\mathrm{N}$ & 1 & 0,23 \\
\hline Azaléia & Rhododendron sp. & Ericaceae & E (Ásia) & 1 & 0,23 \\
\hline $\begin{array}{l}\text { Perna-de- } \\
\text { moça }\end{array}$ & $\begin{array}{l}\text { Brachychiton populneum } \\
\text { (Schott \&Endl.) R. Br. }\end{array}$ & Sterculiaceae & E (Oceania) & 1 & 0,23 \\
\hline $\begin{array}{l}\text { Chapéu-de- } \\
\text { Napoleão }\end{array}$ & $\begin{array}{l}\text { Thevetia thevetioides (Kunth) K. } \\
\text { Schum }\end{array}$ & Apocynaceae & E (México) & 1 & 0,23 \\
\hline Cróton & $\begin{array}{l}\text { Codiaeum variegatum (L.) A. } \\
\text { Juss. }\end{array}$ & Euphorbiaceae & E (Índia) & 1 & 0,23 \\
\hline Ipê-ouro & $\begin{array}{l}\text { Handroanthus albus (Cham.) } \\
\text { Mattos }\end{array}$ & Bignoniaceae & $\mathrm{N}$ & 1 & 0,23 \\
\hline Jambo & Syzygium jambos (L.) Alston) & Myrtaceae & $\mathrm{N}$ & 1 & 0,23 \\
\hline Laranjeira & Cytrus sp. & Rutaceae & $\mathrm{E}$ (Ásia) & 1 & 0,23 \\
\hline Manga & Mangifera sp. & Anacardiaceae & E (Índia) & 1 & 0,23 \\
\hline Moringa & Moringa oleifera Lam. & Moringaceae & $\mathrm{E}$ (Ásia) & 1 & 0,23 \\
\hline $\begin{array}{l}\text { Palmeira- } \\
\text { leque }\end{array}$ & Licuala grandis & Arecaceae & E (Oceania) & 1 & 0,23 \\
\hline Pata-de-vaca & Bauhinia variegata $\mathrm{L}$. & Fabaceae & E (Índia) & 1 & 0,23 \\
\hline $\begin{array}{l}\text { Schefflera- } \\
\text { arbórea }\end{array}$ & $\begin{array}{l}\text { Schefflera arborícola (Hayata) } \\
\text { Merr. }\end{array}$ & Araliaceae & E (Ásia) & 1 & 0,23 \\
\hline
\end{tabular}

O levantamento da arborização dessas avenidas apresenta diversos exemplares de espécies exóticas, totalizando $62 \%$. A Lagerstroemia indica (9,9\%), foi uma das espécies com maior número de exemplares, seguido de Cinnamomum camphora 5,3\%, e Ligustrum lucidum 4,8\%. O plantio de exóticas, espécies introduzidas em ambientes diferentes do qual são originárias, atravessando fronteiras ou outros biomas dentro de limites geopolíticos estabelecidos (MMA, 2006), muitas vezes se dá em função da seleção que os próprios moradores fazem considerando a facilidade de aquisição das mudas, o modismo por algum exemplar e também pela velocidade de crescimento que algumas plantas possuem. Em 2011, Gerhardt encontrou dados semelhantes na área urbana de Santo Cristo-RS. Já em 2008, Coletto havia encontrado resultados similares na cidade de Sete de Setembro-RS.

Dentre os locais de origem das espécies exóticas amostradas no trabalho grande parte das árvores existentes na arborização urbana de Santa Rosa é de origem asiática, refletindo o processo histórico de utilização de essências arbóreas que outrora foram muito 
comuns na arborização européia (ERECHIM, 2011). Neste sentido, a utilização expressiva do ligustro (Ligustrum japonicum), da canela-doce (Cinammomum zeylanicum) e da extremosa (Lagerstroemia indica) reflete a preferência por espécies de rápido desenvolvimento e rusticidade.

Pires et al. (2010) encontrou no município Goiandira-GO, mais de 50\% de espécies exóticas. Oliveira e Carvalho (2010) em algumas vilas de Ponta Grossa-PR, encontram 73\% exóticas. Resultados distintos foram constatados por Faria et al. (2007), o qual constatou a mesma porcentagem de nativas e exóticas nas vias do município de Jacareí-SP.

Quanto às espécies nativas, constatou-se a presença de 163 indivíduos, totalizando $37,6 \%$. Dentre os representantes que se destacaram foram as seguintes espécies Peltophorum dubium (5,5\%), Handroanthus heptaphyllus (5,3\%) e Tabebuia chrysotricha (5,0\%). Essa constatação comprova a tendência observada por pesquisadores como Gonçalves e Paiva (2004) de que o uso de espécies nativas da flora brasileira na arborização urbana é baixo em relação às espécies exóticas. Pode-se notar que espécies frutíferas nativas apresentaram uma população baixa de 7,6\%. Santos e Teixeira (2001) indicam que a frutificação das espécies poderá representar um efeito ornamental e servir de atrativo para a fauna local, mas desaconselham as espécies que produzam frutos grandes como a mangueira, que apresenta frutificação nos meses de setembro a março. Os frutos da mangueira podem pesar entre 250 a 450 gramas, ou até mais, dependendo da variedade (SILVA, 2006), podendo cair sobre a calçada ou sobre pedestres que circulam nas proximidades da planta.

Nas vias estudadas, apenas Lagerstroemia indica L. possui uma frequência de em torno de $10 \%$. No restante possuem frequência menor que 5,6\%. A diversidade de espécies de árvores na paisagem urbana se faz necessária justamente para garantir uma melhor estética, maior disponibilidade de recursos para a fauna urbana e o máximo de proteção contra pragas e doenças (SILVA, 2000).

Com relação à fitossanidade foram encontrados $2,8 \%$ das plantas com situação regular e ruim, onde, nestes casos, os exemplares possuíam algumas ervas de passarinho ou injurias mecânica ou sua morfologia estrutural totalmente descaracterizada. As demais plantas analisadas não apresentaram nenhum sinal aparente de algum tipo de doença, tendo, portanto, um bom aspecto de vigor e saúde, e também aquelas em fase senil.

No decorrer do trabalho verificou-se que $13 \%$ dos indivíduos analisados apresentaram interferência, com exemplares encostando-se à rede elétrica ou postes de energia ou próximos que poderiam vir a encostar-se à rede elétrica. Pode-se ver que em alguns locais onde havia árvores de grande porte, como a Peltophorum dubium, a rede 
elétrica passava no canteiro central ou do outro lado da rua. Para a RGE (2012) a canafístula (Peltophorum dubium) é mais indicada para estacionamentos. Por outro lado, Pivetta e Filho (2002) destacam que árvores com copa muito grande interferem na passagem de veículos e rede elétrica, além de sofrerem danos que prejudicam seu desenvolvimento natural. Para fins práticos, é importante conhecer o desenvolvimento da copa, para adequá-la ao espaço aéreo disponível, pois, se incompatível, essa medida pode trazer transtornos para o transito e para os moradores (SCHUCH, 2006).

Lorenzi (2003) constata que, nas calçadas de ruas sob rede elétrica apenas espécies com menos de $8 \mathrm{~m}$ de altura, quando adultas, podem ser implantadas. Da mesma forma, em calçadas de ruas estreitas, somente espécies de copa estreita e alta ou piramidal devem ser implantadas para evitar a obstrução das vias pelo crescimento excessivo dos ramos laterais. No diagnóstico observou-se que a forma da copa das árvores variou de arredondada a cônica e monopodial. Enquanto que o diâmetro da copa variou conforme a espécie e idade da mesma. Segundo a CEMIG (2001), o plantio sob rede elétrica deve ser feito com árvores de pequeno porte em posição alternada com a arborização do outro lado da rua. Já na calçada onde não existe a rede elétrica, pode-se utilizar espécies de médio porte, adequadas à paisagem local e ao espaço disponível.

Além das observações acima citadas, ainda constata-se algumas características inerentes a determinados grupos vegetais que devem ser levadas em consideração, quando do seu cultivo na área urbana. Tal situação pode ser exemplificada como muitas espécies, como da família Cupressaceae as quais são inadequadas à arborização urbana. Andreatta et al. (2011) afirma que muitas espécies desta família são indicadas para uso em parques e praças, pois na calçada há a necessidade de elevação da copa o que deforma a sua estrutura e apresenta suscetibilidade. Outro caso, seria da Duranta repens e do Buxus sp. que são mais indicados para o paisagismo, porém como podem ser moldados, são bastante aceitos no plantio nos centros da cidade

As árvores que apresentaram problemas de suas raízes em relação a calçadas correspondem 6,5\%. Neste sentido, Faria et al. (2007), salientam que o sistema superficial é apontado como causador do maior prejuízo às calçadas, e que principalmente passeios estreitos, que são comuns em cidades mais antigas, sendo as calçadas não tão bem estruturadas, o que não permite o bom desenvolvimento de raízes de árvores de médio e grande porte. No levantamento foi constatado que as raízes soerguem as calçadas (que possuem entre 1,40 $\mathrm{m}$ a $2 \mathrm{~m}$ de largura) por falta de espaço livre para o sistema radicular se desenvolver. Além disso, observou-se que os moradores costumam cimentar as calçadas até as proximidades do caule das plantas, dificultando o crescimento das mesmas, 
principalmente no que se refere o sistema radicular. As calçadas encontram-se em bom estado, exceto aquelas que apresentam danificações ocasionadas pelas raízes, por falta de atenção no momento da seleção da espécie para o devido local ou pelo pouco espaço destinado para a planta. Segundo Silva (2011), as rachaduras nas calçadas, geralmente ao redor das árvores, ocorrem devido ao fato de estas plantas estarem cimentadas até a base do seu tronco. Desta maneira, não ocorre infiltração de água e nem aeração do solo, sendo que as plantas precisam destes elementos para sobreviver, pois numa medida de sobrevivência, as raízes quebram a calçada em busca destes recursos que lhe faltam. Tal fato foi constatado no decorrer desta pesquisa em que alguns indivíduos onde o espaço destinado ao desenvolvimento do vegetal era bastante escasso, sendo muitas vezes coberto por concreto até o seu tronco, sem deixar local para o sistema radicular acomodar-se. Estes resultados corroboram com o de Felippe (2012) que no seu estudo em Frederico Westphalen- RS, identificou a ausência de área livre para o seu desenvolvimento, com a pavimentação ou a calçada encostando-se ao tronco. Ao considerar o espaço destinado à árvore, Gonçalves (1997) indica uma área livre de um metro quadrado como mínimo a ser destinado para um bom desenvolvimento das árvores plantadas em vias públicas.

Uma das formas de se evitar problemas no desenvolvimento do sistema radicular é através da seleção de uma área permeável ao redor da planta com o uso de cobertura vegetal (gramas ou forragens), na forma de canteiro ou faixa, que permita a infiltração de água e a aeração do solo. As chamadas de "calçadas verdes trazem benefícios tanto para a árvore como para a rua, pois ocorre um aumento das áreas permeáveis a água, possibilitando maior infiltração, diminuindo o volume de água das chuvas nas tubulações (SILVA, 2011).

Outro fator de relevância destacado nesta pesquisa é que a Avenida Tuparendi, juntamente com a Rua Henrique Gassen, soma uma área de via pública extensa, e que apresenta diversos pontos com ausência de qualquer vegetação tanto arbórea quanto arbustiva. Tal característica provavelmente se deve em função de que estes locais estão em fase de novos loteamentos e, consequentemente, a presença de implantação de construções comerciais onde há grande fluxo de veículos.

\section{CONCLUSÕES}

Os resultados do levantamento revelam que as vias de Santa Rosa possuem diversas espécies vegetais, havendo predominância de exóticas em relação às nativas, 
porém, muitas delas são cultivadas em locais inadequados para o seu porte, devido à presença de rede elétrica e/ou calçadas.

Para evitar alguns problemas que foram observados seria necessária fiscalização eficaz, contar com alternativas de uma boa gestão e políticas públicas na área de educação ambiental, a fim de que se possa obter sucesso e usufruir dos benefícios de uma arborização urbana bem planejada. Sugere-se a revitalização das avenidas especialmente com espécies nativas adequadas a arborização e adaptadas a região e que valorizem o paisagismo ecológico do município de Santa Rosa.

\section{REFERÊNCIAS}

ANDREATTA, T.R. BACKES, F. A. A. L.; BELLÉ, R. A.; NEUHAUS, M.; GIRARDI, L. B.; SCHWAB, N. T.; BRANDÃO, B. S. Análise da arborização no contexto urbano de avenidas de Santa Maria, RS. Revista da Sociedade Brasileira de Arborização Urbana, Piracicaba, v.6, n.1, p.36-50, 2011.

BACKES, P; IRGANG, B. Árvores do Sul: guia de identificação e interesse ecológico. Santa Cruz do Sul: Instituto Souza Cruz, 2002.

BLUM, C.T.; BORGO, M.; SAMPAIO, A.C.F. Espécies exóticas invasoras na arborização de vias públicas de Maringá-PR. Revista da Sociedade Brasileira de Arborização Urbana, Piracicaba, v.3, n.2, p.78-97, jun. 2008.

BOENI, B de O; SILVEIRA, D. Diagnóstico da arborização urbana em bairros do município de Porto Alegre, RS, Brasil. Revista da Sociedade Brasileira De Arborização Urbana. Piracicaba, v.6, n.3, 2011.

CEMIG - COMPANHIA ENERGÉTICA DE MINAS GERAIS. Manual de arborização. Belo Horizonte: Superintendência do Meio Ambiente/CEMIG, 2001.

COSTA, E.C; LINK, D; MEDINA, L.D. de. Índice de Diversidade para entomofauna da Bragatinga (Mimosa scabrella Benth.), Ciência Florestal, Santa Maria, v.3, n.1, p. 65-75, 1993.

COLETTO, E. P; MULLER, N.G; WOLSKI; S.S. Diagnóstico da arborização das vias públicas do município de sete de setembro - RS. Revista da Sociedade Brasileira de Arborização Urbana, Piracicaba, v.3, n.2, p.110-122, 2008. 
DANTAS, I. C; SOUZA, C.M. C. Arborização urbana na cidade de Campina Grande-PB: Inventário e suas espécies. Revista de Biologia e Ciências da Terra. Paraíba, v.4, n.2, 2004.

ERECHIM, Prefeitura Municipal de. Plano Diretor de Arborização Urbana do Município de Erechim, RS. Secretaria Municipal do Meio Ambiente: Erechim, 2011.

FARIA, J.L.G; MONTEIRO, E.A; FISCH, S.T.V. Arborização de vias públicas do Município de Jacareí - SP. Revista da Sociedade Brasileira de Arborização Urbana, Piracicaba , v. 2, n.4, p. 20-33, 2007.

FELIPPE, D.; PIAZZA, E. M.; RIL, F. L.; ALBARELO, E.; GALLIO, E.; POCZWARDOWSKI, D.; MANTOVANI, N. Levantamento quali-quantitativo da arborização urbana na Rua monsenhor Vitor Batistela do município de Frederico Westphalen-RS. Disponível em <http://www.unifra.br/eventos/sepe2012/Trabalhos/6769.pdf>. Acesso em: 26 de jun. 2013.

GERHARDT, M.C; MULLER, N. G; WOLSKI, S.R.S. Diagnóstico da arborização da área central da cidade de Santo Cristo - RS. Revista da Sociedade Brasileira de Arborização Urbana. Piracicaba, v.6, n.1, p.69-84, 2011.

GIEHL, E.L.H. (Coord.) 2012. Flora Digital do Rio Grande do Sul e de Santa Catarina. Disponível em <http://ufrgs.br/floradigital>. Acesso em: maio de 2013.

IBGE, Instituto Brasileiro De Geografia e Estatística. Censo Demográfico 2010. Disponível em <http://www.ibge.gov.br/cidadesat/painel/painel.php?codmun=431720> Acesso em: 8 de nov. 2012.

Instituto Brasileiro De Geografia e Estatística. Manual Técnico da Vegetação Brasileira. Rio de Janeiro, 1992. In: Projeto Biodiversidade RS. Disponível em $<\mathrm{http}$ ://www.biodiversidade.rs.gov.br/portal/index.php?acao=secoes_portal\&id=26\&submenu $=14>$. Acesso em: 02 de jun. 2013.

JÚNIOR, L. S. A importância da arborização urbana. Rio de Janeiro, 2011. Disponível em: http://envolverde.com.br/ambiente/urbano/a-importancia-da-arborizacao-urbana/. Acesso em: 23 maio de 2012.

LORENZI, H. Árvores Brasileiras. Manual de identificação e cultivo de plantas arbóreas nativas do Brasil. Nova Odessa: Instituto Plantarum, v.1, 4. ed. São Paulo: 2002.

H. Árvores brasileiras: manual de identificação e cultivo de plantas arbóreas nativas do Brasil. Nova Odessa: Instituto Plantarum, vol.3, 2009.

LORENZI, H.; SOUZA, H. M. de; TORRES, M. A. V.; BACHER, L. B. Árvores exóticas no Brasil: madeireiras ornamentais e aromáticas. Nova Odessa: Instituto Palntarum, 2003. 
LORENZI, H.; SOUZA, H. M. Plantas ornamentais no Brasil: arbustivas, herbáceas e trepadeiras. Nova Odessa: Instituto Plantarum, 2008.

MILANO, M.S.; DALCIN, E. Arborização de vias públicas. Rio de Janeiro: Light, 2000.

MMA. 2006. Ministério do Meio Ambiente. Espécies Exóticas Invasoras: situação brasileira. Brasília. Ministério do Meio Ambiente, 2006.

MOTTER, N; MULLER, N. G. Diagnóstico da arborização urbana no município de Tuparendi-RS. Revista da Sociedade Brasileira de Arborização Urbana, Piracicaba, v.7, n.4, p. 27-36, 2012.

OLIVEIRA, A.C.R; CARVALHO, S.M. Arborização de vias públicas e aspectos sócioeconômicos de três vilas de Ponta Grossa, PR. Revista da Sociedade Brasileira de Arborização Urbana, Piracicaba, v.5, n.3, 2010.

PIRES, N.A.M.T; MELO, M.da S; OLIVEIRA, D.E. de; XAVIER-SANTOS,S. A arborização urbana no município de Goiandira/GO- caracterização quali-quantitativa e proposta de manejo. Revista da Sociedade Brasileira de arborização urbana, Piracicaba, v.5, n.3, p.185-205, 2010.

PIVETTA, K. F.L.; SILVA FILHO, D. F. da. Arborização Urbana. Boletim Acadêmico. Série Arborização Urbana. Unesp, Fcav, Funep. São Paulo, 2002.

RIO GRANDE DO SUL. Projeto RS Biodiversidade. Disponível em <http://www.biodiversidade.rs.gov.br>. Acesso em: 13 nov. 2012.

RGE - RIO GRANDE ENERGIA - Disponível em <http://www.rge-rs.com.br/ Default. aspx?tabid=351\&language=en-US>. Acesso: em 27 de jun. 2013.

ROSA, P.O. O gênero Myrcia DC. (Myrtaceae) nos campos rupestres de Minas Gerais. 2009. 71p. Dissertação (Mestrado em Ecologia e Conservação de Recursos Naturais) Universidade Federal de Uberlândia. Uberlândia, 2009.

SANTOS, N.R.Z.; TEIXEIRA, I.F. Arborização de vias públicas: ambiente $\mathbf{x}$ vegetação. Porto Alegre: Instituto Souza Cruz. Ed.Pallotti, 2001.

SILVA, A. A.(Org.). Guia de Arborização Urbana, Prefeitura Municipal de Hortolândia, Hortolândia, 2011. Disponível em <http://www.hortolandia.sp.gov.br/verdeazul/arquivos/ guiaarborizacao_web.pdf>. Acesso: em 28 de jun.2013.

SILVA, A. G. Arborização urbana em cidades de pequeno porte: avaliação quantitativa e qualitativa. 2000. 150 p. Dissertação (Mestrado em Ciências Florestais), Universidade Federal de Viçosa, Viçosa, 2000. 
SILVA, M.G.C. Florescimento e frutificação de Mangueira (Mangifera indica L.) Cv Rosa promovido por diferentes doses de paclobutrazol. 2006. 66 p. Dissertação (Mestrado EM Agronomia) Universidade Estadual do Sudoeste da Bahia, Bahia, 2006.

SCHUCH, M. I. S. Arborização Urbana: uma contribuição à qualidade de vida com o uso de geotecnologias. 2006. 102p. Dissertação (Mestrado em Geomática), Universidade Federal de Santa Maria. Santa Maria, Rio Grande do Sul, 2006. 